\title{
Nitric Oxide: The Key Molecule for Polyphenols Antimicrobial Action
}

\author{
Loris Grossi*, Raffaella Casadei \\ Dipartimento di Scienze per la Qualità della Vita, Università di Bologna, Campus di Rimini, Corso d'Augusto, Rimini, Italy \\ Email: ${ }^{*}$ loris.grossi@unibo.it, r.casadei@unibo.it
}

How to cite this paper: Grossi, L. and Casadei, R. (2020) Nitric Oxide: The Key Molecule for Polyphenols Antimicrobial Action. Journal of Biosciences and Medicines, 8, 153-165.

https://doi.org/10.4236/jbm.2020.83014

Received: January 13, 2020

Accepted: March 17, 2020

Published: March 20, 2020

Copyright $\odot 2020$ by author(s) and Scientific Research Publishing Inc. This work is licensed under the Creative Commons Attribution International License (CC BY 4.0).

http://creativecommons.org/licenses/by/4.0/

(c) (i) Open Access

\begin{abstract}
The role of hydroxycinnamic acids as antioxidants, in vivo, has been widely discussed, but, recently, a great debate has focused on their antimicrobial action. In general, for the hydroxycinnamic acids' action, the presence of NO, which is known to be an antimicrobial agent, seems compulsory; its production goes through the intermediacy of the nitrosonium ion, and a very low $\mathrm{pH}$, for instance, as in the stomach, is requested. However, the action of the hydroxycinnamic acids seems to take place even in different biological compartments, i.e., characterized by different $\mathrm{pHs}$ and conditions, and then, for NO production, an alternative mechanism could be involved. In this light, evidence for the NO formation, via an E.T. mechanism, even in mildly acidic conditions $(\mathrm{pH}=6.4)$, was obtained by reacting an aqueous buffer solution of acidic nitrite $\left(\mathrm{HNO}_{2}\right)$ with the hydroxycinnamic acids ferulic, caffeic, p-coumaric and sinapic. Experiments conducted by EPR spectroscopy, let to detect the NO formation, and the efficiency of the process depending on the available amount of free polyphenol, and the intrinsic nature of the hydroxycinnamic acids. Thus, the production of NO through a non-enzymatic mechanism, in light acidic conditions, would account for the antimicrobial action of hydroxycinnamic acids, even in unconventional biological compartments, and for $\mathrm{NO}$ as the key-molecule.
\end{abstract}

\section{Keywords}

Hydroxycinnamic Acids, Nitric Oxide, Antioxidant, Antimicrobial, EPR Spectroscopy

\section{Introduction}

Reactive Oxygen Species (ROS), and Reactive Nitrogen Species (RNS) have been recognized to play a fundamental role in the pathogenesis of several chronic and degenerative diseases, leading to increase the interest in antioxidants as prophy- 
lactic or therapeutic agents. To investigate the harmful action of these radical species, most of the work was focusing on vitamin E, ascorbate, and carotenoids [1], but, during the last decade, food polyphenols have received more attention [2]-[6]. Thus, several studies for the identification of polyphenols, better absorbed and/or forming active metabolites have been carried out [7].

To account for polyphenols' action, NO is often invoked as the active intermediate and, for its production, besides an enzymatic path, an electron transfer process possible even at $\mathrm{pH}$ slightly lower than physiological is hypothesized [8] [9] [10] [11]. In particular, previous studies on sulfur derivatives commonly used as antimicrobials, antioxidants and food preservatives [12] [13], showed the ability of these species to act as cofactors of nitrous acid inducing NO release via an E.T. mechanism [14] (Scheme 1(a)). As well, studies conducted on the reaction between p-coumaric, ferulic, and caffeic acid, and acid nitrite $\left(\mathrm{HNO}_{2}\right)$, reported the formation of nitrous and nitro derivatives through the intermediacy of NO [15] [16] [17] [18]. All these results support the E.T. mechanism and, as well, emphasize the prominent role of acid $\mathrm{pHs}$ in the aqueous/biological medium, as demonstrated by the abundant production of $\mathrm{NO}$ in the stomach $(\mathrm{pH}<$ 2) [19]; but, the NO production, in very acidic conditions, is believed to proceed through a different mechanism (Scheme 1(b)). In fact, at first, the nitrosonium ion $\left(\mathrm{NO}^{+}\right)$is formed, which is rapidly reduced to $\mathrm{NO}$ to pass into the gaseous phase (Henry's law), and then eliminated by expiration. Such a mechanism makes the production and removal of NO very dynamic, and then too low the residual amount of NO in the gastric juice to account for the many biochemical effects attributable to its permeability through the stomach wall. So, other mechanisms of NO production and different mechanisms of action must be involved (Scheme 1).

To understand the role/action of polyphenols, it also needs to consider their chemical structures. In fact, these species are ingested mainly as glycosides, very soluble in water and then quickly excreted, and to obtain free polyphenols, which are the reactive species, it is necessary to a chemical process led by digestive activities and liver changes [20] [21] [22] [23]. It follows that the amount of glycosides that will remain available is low, and therefore the amount of free polyphenols in circulation insufficient to contribute to the total antioxidant capacity. In light of this, it is necessary to stress that the entire antioxidant system, in vivo,

a)

$$
\begin{aligned}
& \mathrm{H}_{3} \mathrm{O}^{+}+\mathrm{NO}_{2} \stackrel{\text { pH=6.4 }}{\rightleftharpoons} \mathrm{HO}-\mathrm{NO}+\mathrm{H}_{2} \mathrm{O} \\
& \text { HO-NO } \underset{\text { Reductants }}{\stackrel{+\mathrm{e}^{-} / \mathrm{E} . \mathrm{T} .}{\longrightarrow}} \dot{\mathrm{NO}}+\mathrm{HO}^{-} \\
& \text {Reductants }=\mathrm{H}_{2} \mathrm{~S}, \mathrm{HSO}_{3}{ }^{-}, \mathrm{GSH}
\end{aligned}
$$

b)

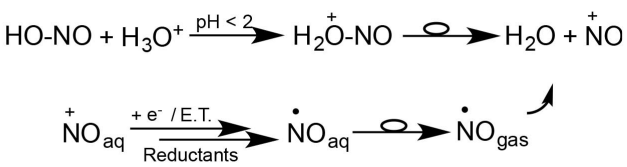

Scheme 1. The mechanism of NO production as a function of $\mathrm{pH}$ : (a) At slightly acidic pHs; (b) At very acidic pHs. 
is usually in equilibrium, then exogenous antioxidants could play a role only if this equilibrium breaks down [24] [25], and if they are in the right place at the right time. Finally, the ability of exogenous antioxidants to trap ROS largely depends on phenolic hydroxyl groups and, in a biological medium, a sequential proton-loss/electron-transfer appears to be the main route of action [26]; this lets to consider the transfer of signal, and the protection from microorganisms their primary biological role [25] [27] [28] [29] [30]. In this work, we set out experiments at different substrate concentrations and constant $\mathrm{pH}$, hypothesizing the NO production through an E.T. mechanism [14]. In particular, we studied the effect of polyphenolic compounds, i.e., cinnamoyl derivatives such as the ferulic, caffeic, p-coumaric and sinapic acids, on the concentration of released NO when reacting with an aqueous nitrite solution; to do this, the detection of the adduct of $\mathrm{NO}$ with $\mathrm{Fe}^{++}(\mathrm{DETC})_{2}$, by EPR spectroscopy, was used as outlined in the next section. In particular, such a technique allows to detect the formation of $\mathrm{NO}$ independently of the medium's $\mathrm{pH}$, and then even in conditions different from those of compartments in which the NO production seems appointed; this would support the involvement of new pathways for NO formation, and new mechanisms of action (Scheme 2).

\section{Material and Methods}

\subsection{Materials}

All experiments have been conducted at room temperature with commercial products, ferulic, caffeic, p-coumaric and sinapic acids, at the highest degree of purity, except the $\mathrm{Fe}^{++}(\mathrm{DETC})_{2}$, iron(II) N, N-diethyldithiocarbamate, which was synthesized as follows: $25 \mathrm{~mL}$ of a water solution of diethyldithiocarbamate (DETC), $20 \mathrm{mmol} / \mathrm{L}$, were added to $100 \mathrm{~mL}$ of a water solution of $\mathrm{FeSO}_{4} \cdot 7 \mathrm{H}_{2} \mathrm{O}$, $10 \mathrm{mmol} / \mathrm{L}$, over a $60-\mathrm{min}$ period. The mixture was stirred for two hours, and the precipitate, $\mathrm{Fe}^{++}(\mathrm{DETC})_{2}$, collected by filtration; the process was conducted in a rigorous nitrogen atmosphere. The buffer solution was freshly prepared, and the solvents, $\mathrm{CH}_{2} \mathrm{Cl}_{2}$ and $\mathrm{CH}_{3} \mathrm{OH}$, spectroscopic degree.

\subsection{EPR Experiments}

Samples were prepared using a device formed by two vials, equipped with a

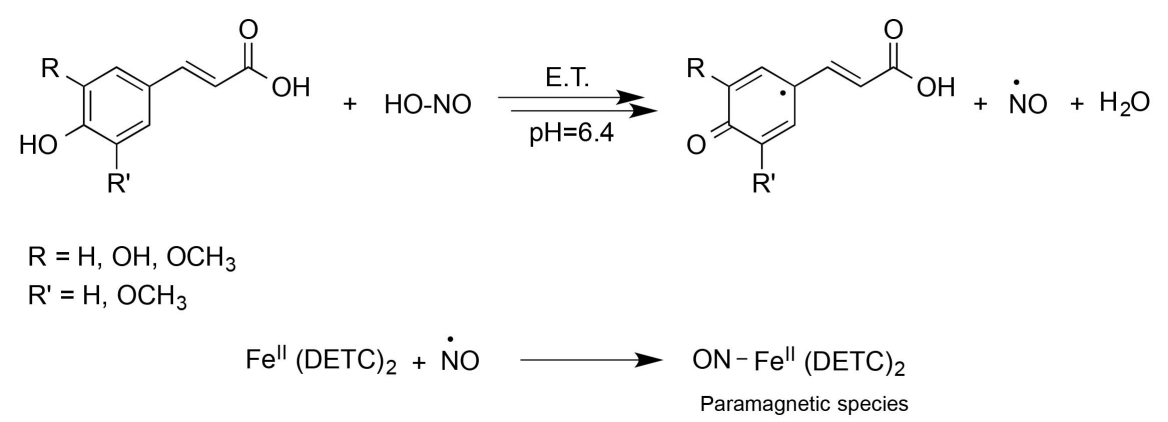

Scheme 2. Reaction between hydroxycinnamic acids and $\mathrm{HNO}_{2}$, in light acidic conditions. 
porous septum and connected by means of a tiny PTFE tube; in the first vial, 3.0 $\mathrm{mL}$ of a buffer solution $(\mathrm{pH}=6.4)$ of $\mathrm{NaNO}_{2}(1.0 \mathrm{mM})$ and variable amounts of polyphenols, in ratio 1:3:5, were reacted. The second vial was filled with $3.0 \mathrm{~mL}$ of a $\mathrm{CH}_{2} \mathrm{Cl}_{2}$ solution of the spin trap, $\mathrm{Fe}^{++}(\mathrm{DETC})_{2},(3.0 \mathrm{mM})$. In particular, methanolic stock solutions of ferulic, caffeic, and p-coumaric acids were prepared and, from these, reference solutions at concentration of $1.29 \mathrm{mM}, 3.86 \mathrm{mM}$, and $6.44 \mathrm{mM}$, i.e., in ratio 1:3:5. For the sinapic acid, because of its poor solubility in water, the molar extinction coefficient was at first determined by UV-spectroscopy, $\varepsilon_{324}=26849 \mathrm{~mol}^{-1} \cdot \mathrm{dm}^{3} \cdot \mathrm{cm}^{-1}$, and solutions at $2.4 \times 10^{-3} \mathrm{mM}, 7.0 \times 10^{-3} \mathrm{mM}$, and $11.70 \times 10^{-3} \mathrm{mM}$, i.e., in ratio 1:3:5, were then prepared. Concerning chlorogenic and caffeic acid, experiments with solutions $5.0 \times 10^{-3} \mathrm{mM}$ concentration, under the same experimental conditions used for all the substrates, have been carried out; finally, to check if the production of NO can be deriving even from other sources, a blank experiment, i.e., in the absence of polyphenols, was carried out. All samples were prepared by bubbling a stream of $\mathrm{N}_{2}$-gas into the first vial to allow polyphenols to react with $\mathrm{NaNO}_{2}$; afterward, the $\mathrm{N}_{2}$ stream, rich in $\mathrm{NO}$ picked up from the first vial, is forwarded into the second vial containing the methylenic trap-solution, in which the paramagnetic adduct, $\mathrm{NO}-\mathrm{Fe}^{++}(\mathrm{DETC})_{2}$, can be formed. In particular, NO was collected, passing through this solution the $\mathrm{N}_{2} / \mathrm{NO}$ stream for 20 minutes, and then used to carry out the EPR experiments. So, a small aliquot of the solution was introduced into a capillary EPR test-tube and investigated through an EM Brüker EPR spectrometer; the spectra, analyzed through the Win-EPR software (Bruker), were then compared with each other using Microsoft Excel software. Finally, it needs to stress that all experiments were conducted under an inert atmosphere, $\mathrm{N}_{2}$ gas, for avoiding the possible oxidation of NO.

\section{Results and Discussion}

\subsection{Establishing the Production of NO}

As hypothesized in the introduction, for supporting the release/formation of NO through an E.T. mechanism, EPR experiments, using spin-trapping techniques, were conducted.

1) An acidic buffer solution ( $\mathrm{pH}=6.4$ ) of nitrite was reacted with polyphenols such as ferulic, caffeic, p-coumaric and sinapic acids; all experiments allowed to detect an intense EPR signal ascribable to the paramagnetic adduct of NO to the spin trap, NO-Fe ${ }^{++}(\text {DETC })_{2}$. This supported both a non-enzymatic mechanism and the different capacity of each substrate in inducing the release of NO [31] (Figure 1).

2) Relationship between Hydroxycinnamic acids concentration and NO release.

Since the effectiveness of polyphenols as NO inducer might depend on the available amount of free hydroxycinnamic acid and not of glycosides, esters or amides, i.e., the ingested parent species, EPR experiments with pure hydroxycinnamic acids, at variable concentration, have been carried out. In particular, a 


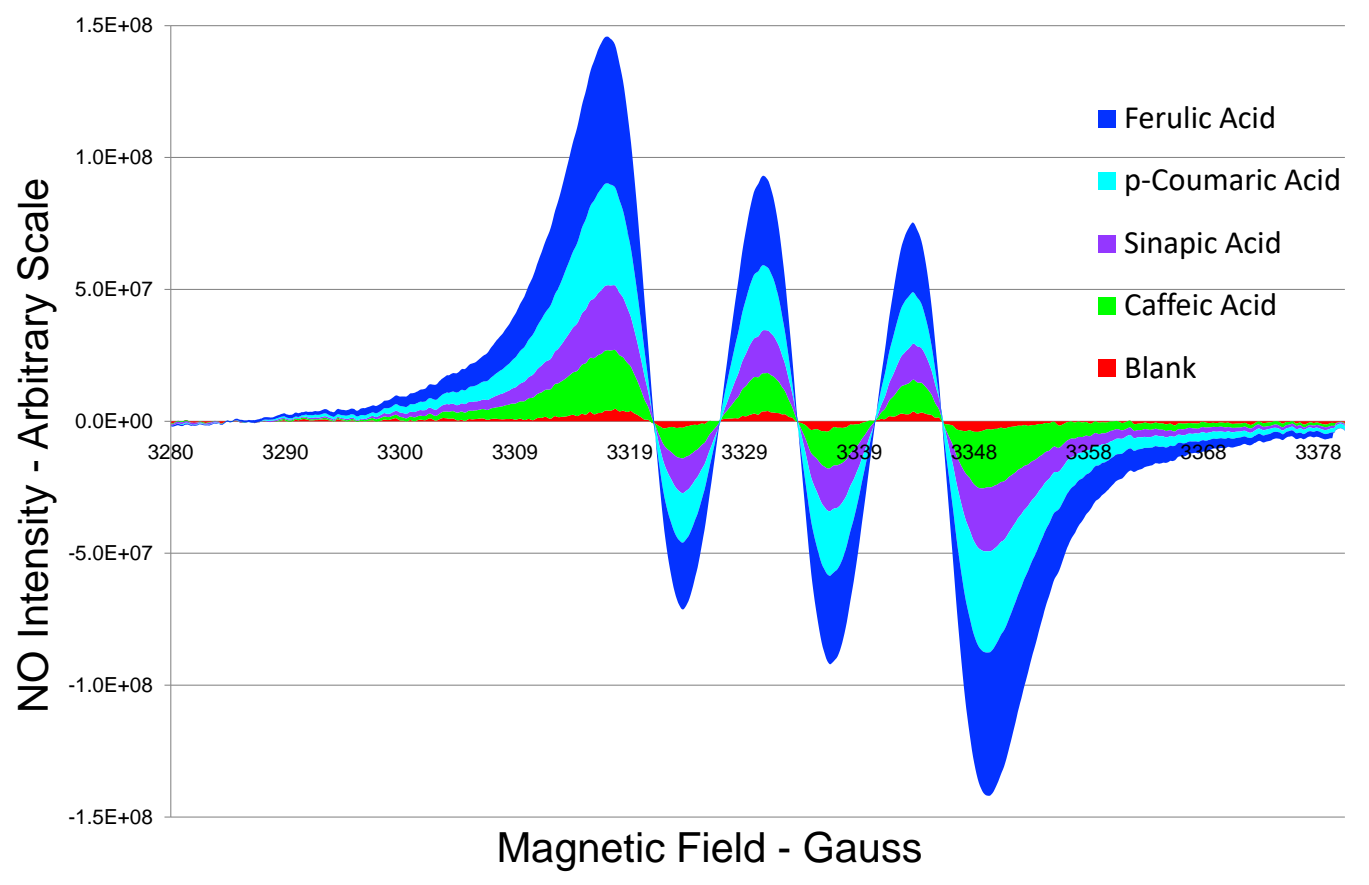

Figure 1. EPR spectra (stacked area) of $\mathrm{NO}-\mathrm{Fe}^{++}(\mathrm{DETC})_{2}, \mathrm{aN}=1.28 \mathrm{mT}$ and $\mathrm{g}=2.039$, detected when reacting the hydroxycinnamic acids (same concentration, $6.44 \mathrm{mM}$ ) with the reference acidic nitrite solution. Blank Experiment: no polyphenol was present.

buffer solution $(\mathrm{pH}=6.4)$ of nitrite was reacted with methanolic solutions of ferulic, p-coumaric, caffeic and sinapic acids, at three different concentrations in ratio 1:3:5 (Figure 2).

The correlation between the amount of NO released/trapped, EPR spectrum area, and the concentration of pure hydroxycinnamic acid used, undoubtedly prove the different intrinsic capacity of each polyphenol to act as NO inducer (Figure 3).

\section{3) The role of the medium.}

The behavior/function of polyphenols often refer to experiments in vitro, and in solvents not com-parable to a biological medium, therefore, different will be their solubility, and then the available amount of free hydroxycinnamic acids. To verify this, we focused our attention on sinapic acid, which is considered both a powerful antioxidant and an antimicrobial agent [31] [32]. Two stock solutions, one aqueous and one methanolic, in which the sinapic acid solubility is markedly different, were prepared. EPR experiments were carried out by reacting these solutions, at three different concentrations, in ratio 1:3:5, with a buffer solution $(\mathrm{pH}=6.4)$ of nitrite; all experiments led to the detection of the paramagnetic adduct of $\mathrm{NO}$ to the trap, NO-Fe ${ }^{++}(\mathrm{DETC})_{2}$ (Figure 4).

Comparing EPR spectra, a direct correlation between the amount of NO released/detected and that of free hydroxycinnamic acid available, independent of the solvent, can be confirmed [32]; but, the role of the solvent is underlined too, in fact, it manages the quantity of available substrate through the solubility (Figure 5). 


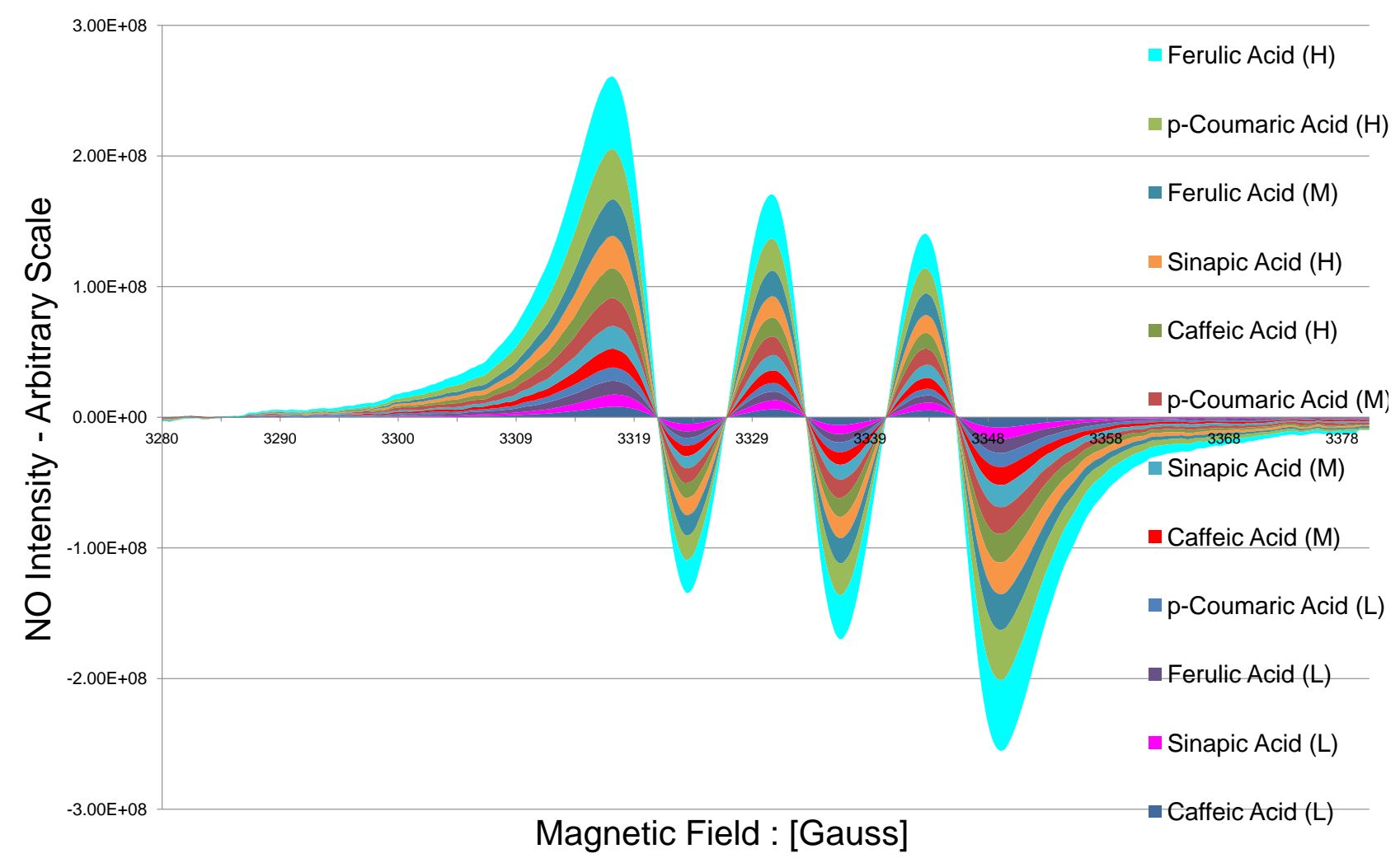

Figure 2. EPR spectra (stacked areas) of the radical NO-Fe ${ }^{++}(\mathrm{DETC})_{2}$, detected with four different hydroxycinnamic acids; three different methanolic solutions at concentrations, in ratio 1:3:5 = (L) $1.29 \mathrm{mM}:(\mathrm{M}) 3.86 \mathrm{mM}:(\mathrm{H}) 6.44 \mathrm{mM}$, were tested. We used methanolic solutions because in this solvent all substrates are soluble enough.

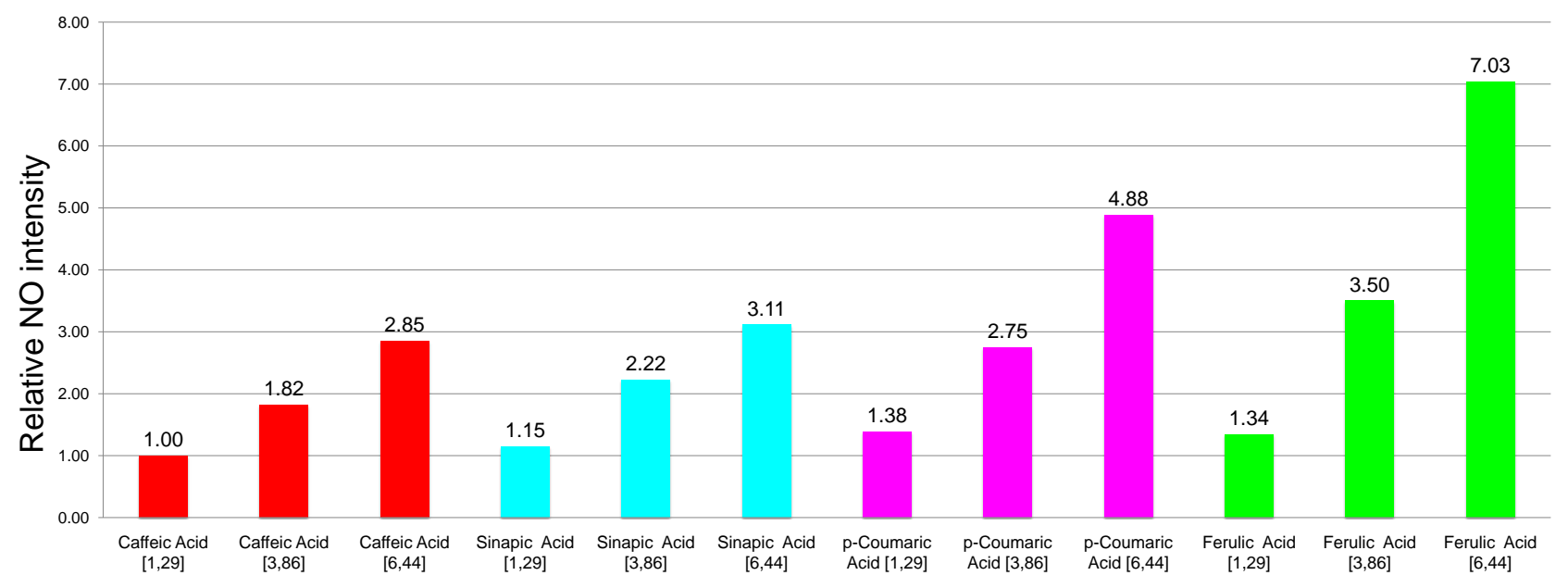

Hydroxycinnamic acid Concentration in Methanol: [mM]

Figure 3. Relative amounts of NO-released as a function of the available free hydroxycinnamic acid. Values are standardized to the lowest detected amount of NO, among all experiments, i.e., [caffeic acid] $=1.29 \mathrm{mM}$.

\subsection{NO, Probably Mediator of the Antioxidant Action as Well?}

Since the formation of NO is the first step of reaction between hydroxycinnamic acids and acidic nitrite [33] [34] (Scheme 2), beside the antimicrobial action might be plausible to hypothesize NO as the key-molecule even for the antioxidant 


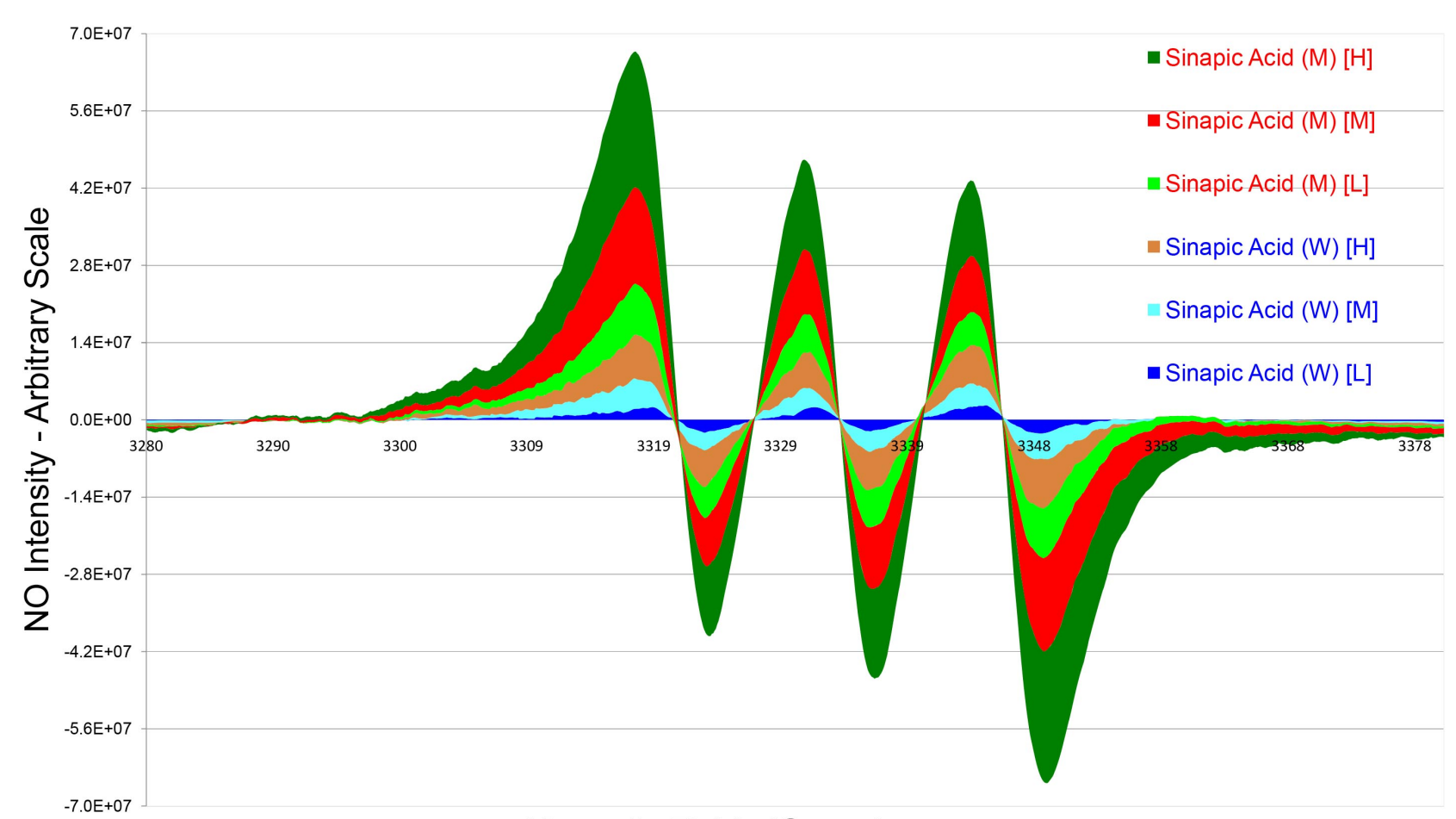

Magnetic Field : [Gauss]

Figure 4. EPR spectra, (stacked area), of NO-Fe ${ }^{++}(\mathrm{DETC})_{2}$. Sinapic acid from different stock solutions, $\mathrm{CH}_{3} \mathrm{OH}(\mathrm{M})$ and $\mathrm{H}_{2} \mathrm{O}(\mathrm{W})$, at different ratio of concentration: 1:3:5 $=[\mathrm{L}]$ Low: $[\mathrm{M}]$ Medium:[H] High.

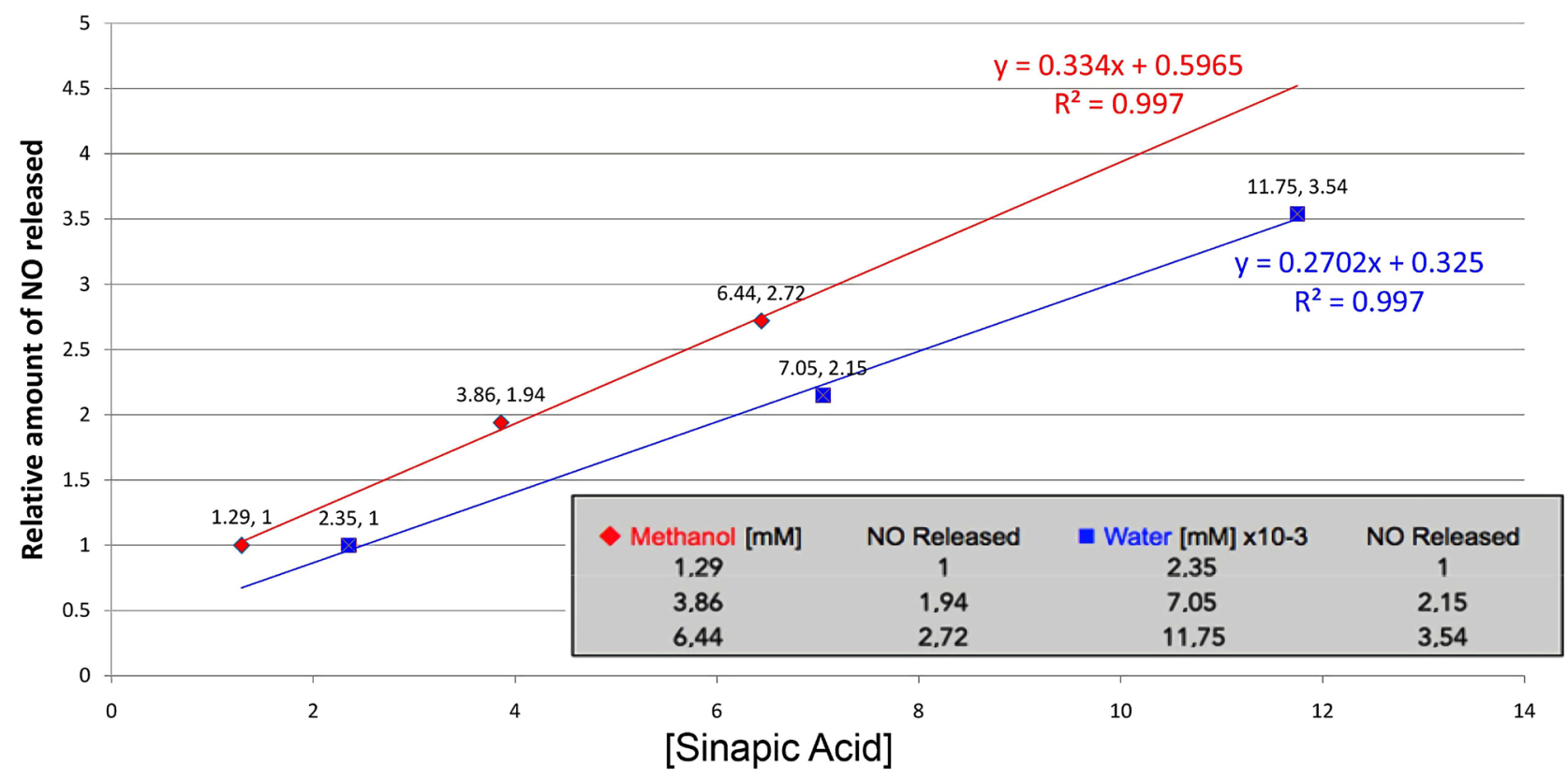

Figure 5. NO released from samples of sinapic acid at different concentrations, in different solvents. $(\diamond) \mathrm{CH}_{3} \mathrm{OH}\left[\mathrm{mM}^{-}\right.$and $(\square)$ $\mathrm{H}_{2} \mathrm{O}[\mathrm{mM}] \times 10^{-3}$. All concentrations used are in the limit of solubility of sinapic acid in water and methanol.

role, i.e., responsible for this action. To support or disclaim this hypothesis, substrates as the chlorogenic and the caffeic acid, widely recognized to be excellent antioxidants, were investigated [35] [36]. EPR experiments, conducted under the 
same experimental conditions, showed the formation of the paramagnetic adduct, NO-Fe ${ }^{++}(\mathrm{DETC})_{2}$, with both substrates, but the NO detected/released by the chlorogenic acid was prevailing over that of caffeic acid, (5.9:1.0), in agreement with its greater antioxidant capacity (Figure 6).

However, since chlorogenic acid also has antimicrobial action, and NO is the main detectable product of the process, it seems reasonable to consider NO involved/responsible for both, the antimicrobial and the antiradical action [37]. This behavior seems to be common to all the investigated hydroxycinnamic acids, thus allowing to consider NO as the active species on behalf of hydroxycinnamic acids actions.

\subsection{The Hypothesized Mechanism of Action}

Several methods, for evaluating the antioxidant capacity of polyphenols, and therefore their anti-radical activity [38], are reported in the literature; among these, the Trolox equivalent antioxidant capacity (TEAC), the DPPH radical scavenging activity, the Efficient Quantity (EC50) [31] [39]-[43], and so on, but all parameters obtained with these techniques result quite scattered if compared each other, i.e., non-coherent. Furthermore, it needs to stress that such values are obtained carrying out experiments in different organic solvents in mixture with water, which strongly influences the final result [38] [39]. More reliable and comparable values for measuring the antimicrobial capacity could be the redox potential [39] [40], even if for these parameters the values are depending on solvent, acidity, etc. Concerning our experiments, other undisclosed processes can be involved and contribute to the final results, such as the dimerization or higher

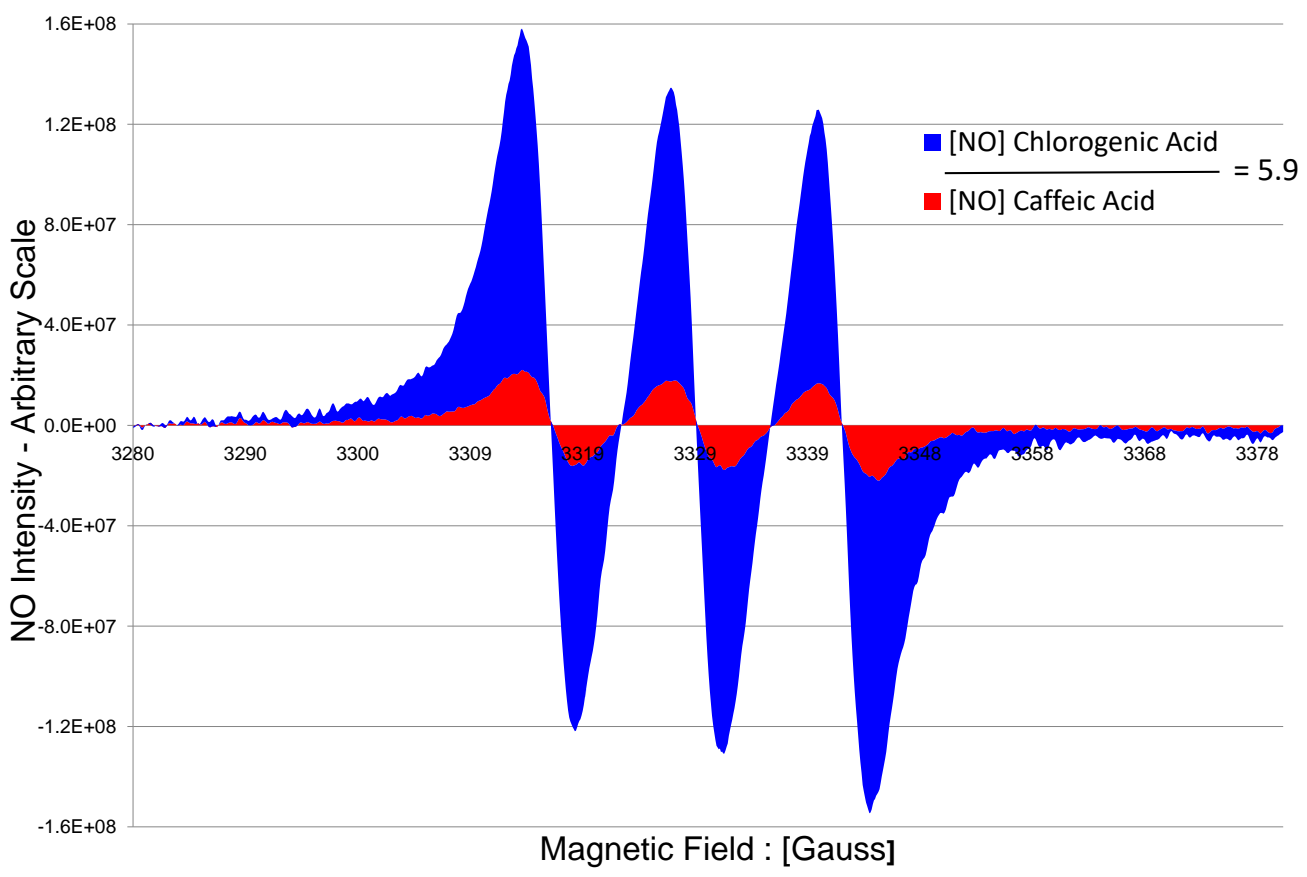

Figure 6. Quantitative comparison of NO released reacting chlorogenic acid ( $\square$ ) and caffeic acid ( $\square$ ), same concentration, with a reference solution of acidic nitrite $\left(\mathrm{HNO}_{2}\right)$. 
polymerization of phenoxy intermediates, which could lead to products still acting as antioxidants and/or antimicrobials [32] [41] [44] as reported for ferulic and coumaric acids present in food [33]. In fact, by thermal processing such as sterilization or cooking, the formation of dimers comes evident, and their antioxidant and antimicrobial action are higher than that of the parent compound [45] [46] [47].

\section{Conclusion}

By EPR spectroscopy we have demonstrated that natural polyphenols, as hydroxycinnamic acids, recognized to have both antimicrobial and antiradical action, can carry out these actions through the NO intermediacy. In fact, the interaction of polyphenols with a buffer solution $(\mathrm{pH}=6.4)$ of acidic nitrite $\left(\mathrm{HNO}_{2}\right)$, suggests an efficient NO release, and this accountable only via non-enzymatic process. Such a mechanism, for the NO production in vivo, was already reported, but, in a very acidic medium as into the stomach and the nitrosonium ion the reactive intermediate. This appears unlike since the antimicrobial action of polyphenols can take place even in compartments characterized by very different $\mathrm{pH}$ values, as supported by studies conducted in vivo on different types of bacteria, and the presence of NO seems necessary, but this achievable only via a non-enzymatic (Electron Transfer) process. Some experiments showed a different efficiency in inducing NO release, i.e., not accountable through the polyphenol's redox potential, and the solubility, as mainly considered; considering this, as suggested in the literature, we assumed that by-products deriving from the polymerization of polyphenols' intermediates are involved, and reducing agents more potent than the parent polyphenols. This study also led to reconsider the antiradical action of polyphenols, as this action might depend on the intermediacy of NO, the main reaction product, and this proved by the study conducted on antioxidants as the chlorogenic and caffeic acids, for testing their NO inducers capability. In definitive, both the antimicrobial and the antioxidant activity of hydroxycinnamic acids can take place even in mildly acidic conditions, and NO the active molecule, whose formation is conceivable only through a non-enzymatic mechanism.

\section{Acknowledgements}

We thank Prof. A. Arcioni, Bologna University, for the Bruker EM-EPR Spectrometer facility.

\section{Conflicts of Interest}

The authors declare no conflicts of interest regarding the publication of this paper.

\section{References}

[1] Benzie, I.F.F. (2000) Evolution of Antioxidant Defence Mechanisms. European 
Journal of Nutrition, 39, 53-61. https://doi.org/10.1007/s003940070030

[2] Schewe, T. and Sies, H. (2005) Myeloperoxidase-Induced Lipid Peroxidation of LDL in the Presence of Nitrite. Protection by Cocoa Flavanols. Bio Factors, 24, 49-58. https://doi.org/10.1002/biof.5520240106

[3] Rice-Evans, C.A., Miller, N.J. and Paganga, G. (1996) Structure-Antioxidant Activity Relationships of Flavonoids and Phenolic Acids. Free Radical Biology and Medicine, 20, 933-956. https://doi.org/10.1016/0891-5849(95)02227-9

[4] Maron, D.J. (2004) Flavonoids for Reduction of Atherosclerotic Risk. Current Atherosclerosis Reports, 6, 73-78. https://doi.org/10.1007/s11883-004-0119-1

[5] Peri, L., Pietraforte, D., Scorza, G., et al. (2005) Apples Increase Nitric Oxide Production by Human Saliva at the Acidic pH of the Stomach: A New Biological Function for Polyphenols with a Catechol Group? Free Radical Biology and Medicine, 39, 668-681. https://doi.org/10.1016/j.freeradbiomed.2005.04.021

[6] Chen, C. (2015) Sinapic Acid and Its Derivatives as Medicine in Oxidative StressInduced Diseases and Aging. Oxidative Medicine and Cellular Longevity, 2016, 1-10. https://doi.org/10.1155/2016/3571614

[7] Scalbert, A. and Williamson, G. (2000) Dietary Intake, and Bioavailability of Polyphenols. Journal of Nutrition, 130, 2073S-2085S.

https://doi.org/10.1093/jn/130.8.2073S

[8] Barone, E., Calabrese, V. and Mancuso, C. (2009) Ferulic Acid and Its Therapeutic Potential as a Hormetin for Age-Related Diseases. Biogerontology, 10, 97-108. https://doi.org/10.1007/s10522-008-9160-8

[9] Ferreira, P.G., Lima, M.A.S.S., Bernedo-Navarro, R.A., et al. (2011) Stimulation of Acidic Reduction of Nitrite to Nitric Oxide by Soybean Phenolics: Possible Relevance to Gastrointestinal Host Defense. Journal of Agricultural and Food Chemistry, 59, 5609-5616. https://doi.org/10.1021/jf201229x

[10] Daglia, M. (2012) Polyphenols as Antimicrobial Agents. Current Opinion in Biotechnology, 23, 174-181. https://doi.org/10.1016/j.copbio.2011.08.007

[11] Beligni, M.V., Fath, A., Bethke, P.C., et al. (2002) Nitric Oxide Acts as an Antioxidant and Delays Programmed Cell Death in Barley Aleurone Layers. Plant Physiology, 129, 1642-1650. https://doi.org/10.1104/pp.002337

[12] Grossi, L. (2009) Hydrogen Sulfide Induces Nitric Oxide Release from Nitrite. Bioorganic \& Medicinal Chemistry Letters, 19, 6092-6094. https://doi.org/10.1016/j.bmcl.2009.09.030

[13] Grossi, L. (2014) Nitric Oxide: Probably the in Vivo Mediator of the Bisulfite's Effects. Journal of Biosciences and Medicines, 2, 1-6. https://doi.org/10.4236/jbm.2014.27001

[14] Rocha, B.S., Gago, B., Barbosa, R.M., et al. (2009) Dietary Polyphenols Generate Nitric Oxide from Nitrite in the Stomach and Induce Smooth Muscle Relaxation. Toxicology, 265, 41-48. https://doi.org/10.1016/j.tox.2009.09.008

[15] Nadtochiy, S.M. and Redman, E.K. (2011) Mediterranean Diet and Cardioprotection: The Role of Nitrite, Poly-Unsaturated Fatty Acids, and Polyphenols. Nutrition, 27, 733-744. https://doi.org/10.1016/j.nut.2010.12.006

[16] Balzer, J., Rassaf, T. and Kelm, M. (2007) Reductase Activity of Polyphenols?: A Commentary on "Red Wine-Dependent Reduction of Nitrite to Nitric Oxide in the Stomach". Free Radical Biology and Medicine, 43, 1226-1228. https://doi.org/10.1016/j.freeradbiomed.2007.07.018

[17] Cotelle, P. and Vezin, H. (2001) Reaction of Caffeic Acid Derivatives with Acidic 
Nitrite. Tetrahedron Letters, 42, 3303-3305.

https://doi.org/10.1016/S0040-4039(01)00441-5

[18] Rousseau, B. and Rosazza, J.P.N. (1998) Reaction of Ferulic Acid with Nitrite: Formation of 7-Hydroxy-6-Methoxy-1,2(4H)-Benzoxazin-4-One. Journal of Agricultural and Food Chemistry, 46, 3314-3317. https://doi.org/10.1021/jf980130f

[19] Carlsson, S., Wiklund, N.P., Engstrand, L., et al. (2001) Effects of pH, Nitrite, and Ascorbic Acid on Non-Enzymatic Nitric Oxide Generation and Bacterial Growth in Urine. Nitric Oxide, 5, 580-586. https://doi.org/10.1006/niox.2001.0371

[20] Cheynier, V. (2005) Polyphenols in Foods Are More Complex than Often Thought. The American Journal of Clinical Nutrition, 81, 223S-229S. https://doi.org/10.1093/ajcn/81.1.223S

[21] Manach, C., Williamson, G., Morand, C., et al. (2005) Bioavailability and Bioefficacy of Polyphenols in Humans. I. Review of 97 Bioavailability Studies. The American Journal of Clinical Nutrition, 81, 230S-242S. https://doi.org/10.1093/ajcn/81.1.230S

[22] Williams, R.J., Spencer, J.P.E. and Rice-Evans, C. (2004) Flavonoids: Antioxidants or Signalling Molecules? Free Radical Biology and Medicine, 36, 838-849.

https://doi.org/10.1016/j.freeradbiomed.2004.01.001

[23] Clifford, M.N. (2004) Diet-Derived Phenols in Plasma and Tissues and Their Implications for Health. Planta Medica, 70, 1103-1114. https://doi.org/10.1055/s-2004-835835

[24] Shen, L., Ji, H.-F. and Zhang, H.-Y. (2007) How to Understand the Dichotomy of Antioxidants. Biochemical and Biophysical Research Communications, 362, 543-545. https://doi.org/10.1016/j.bbrc.2007.07.125

[25] Kadoma, Y. and Fujisawa, S. (2008) A Comparative Study of the Radical-Scavenging Activity of the Phenol-Carboxylic Acids Caffeic Acid, P-Coumaric Acid, Chlorogenic Acid and Ferulic Acid, with or without 2-Mercaptoethanol, a Thiol, Using the Induction Period Method. Molecules, 13, 2488-2499.

https://doi.org/10.3390/molecules13102488

[26] Litwinienko, G. and Mulder, P. (2009) Comment on "Temperature and Solvent Effects on Radical Scavenging Ability of Phenols". The Journal of Physical Chemistry A, 113, 14014-14016. https://doi.org/10.1021/jp908635k

[27] Ji, H.-F., Li, X.-J. and Zhang, H.-Y. (2009) Natural Products and Drug Discovery. EMBO Reports, 10, 194-200. https://doi.org/10.1038/embor.2009.12

[28] Middleton, E., Kandaswami, C. and Theoharides, T.C. (2000) The Effects of Plant Flavonoids on Mammalian Cells: Implications for Inflammation, Heart Disease, and Cancer. Pharmacological Reviews, 52, 673-751.

[29] Stevenson, D.E. and Hurst, R.D. (2007) Polyphenolic Phytochemicals: Just Antioxidants or Much More? Cellular and Molecular Life Sciences, 64, 2900-2916. https://doi.org/10.1007/s00018-007-7237-1

[30] Maurya, D.K. and Devasagayam, T.P.A. (2010) Antioxidant and Prooxidant Nature of Hydroxycinnamic Acid Derivatives Ferulic and Caffeic Acids. Food and Chemical Toxicology, 48, 3369-3373. https://doi.org/10.1016/j.fct.2010.09.006

[31] Nićiforović, N. and Abramovič, H. (2013) Sinapic Acid and Its Derivatives: Natural Sources and Bioactivity. Comprehensive Reviews in Food Science and Food Safety, 13, 34-51. https://doi.org/10.1111/1541-4337.12041

[32] Natella, F., Nardini, M., Di Felice, M., et al. (1999) Benzoic and Cinnamic Acid Derivatives as Antioxi-Dants: Structure-Activity Relation. Journal of Agricultural and 
Food Chemistry, 47, 1453-1459. https://doi.org/10.1021/jf980737w

[33] Robbins, R.J. (2003) Phenolic Acids in Foods: An Overview of Analytical Methodology. Journal of Agricultural and Food Chemistry, 51, 2866-2887. https://doi.org/10.1021/jf026182t

[34] Cueva, C, Moreno-Arribas, M.V., Martín-Álvarez, P.J., et al. (2010) Antimicrobial Activity of Phenolic Acids against Commensal, Probiotic and Pathogenic Bacteria. Research in Microbiology, 161, 372-382. https://doi.org/10.1016/j.resmic.2010.04.006

[35] Heinrich, T.A., da Silva, R.S., Miranda, K.M., et al. (2013) Biological Nitric Oxide Signalling: Chemistry and Terminology. British Journal of Pharmacology, 169, 1417-1429. https://doi.org/10.1111/bph.12217

[36] Kono, Y., Kobayashi, K., Tagawa, S., et al. (1997) Antioxidant Activity of Polyphenolics in Diets. Rate Constants of Reactions of Chlorogenic Acid and Caffeic Acid with Reactive Species of Oxygen and Nitrogen. Biochimica et Biophysica Acta-General Subjects, 1335, 335-342. https://doi.org/10.1016/S0304-4165(96)00151-1

[37] Darley-Usmar, V.M., Patel, R.P., O’Donnel, V.B., et al. (2000) Biology and Pathobiology, Antioxidant Actions of Nitric Oxide. In: Ignarro, L.J., Ed., Nitric Oxide, Academic Press, San Diego, CA, 265-276. https://doi.org/10.1016/B978-012370420-7/50018-6

[38] van den Berg, R., Haenen, G.R.M.M., van den Berg, H. and Bast, A. (1999) Applicability of an Improved Trolox Equivalent Antioxidant Capacity (TEAC) Assay for Evaluation of Antioxidant Capacity Measurements of Mixtures. Food Chemistry, 66, 511-517. https://doi.org/10.1016/S0308-8146(99)00089-8

[39] Hotta, H., Nagano, S., Ueda, M., et al. (2002) Higher Radical Scavenging Activities of Polyphenolic Antioxidants Can Be Ascribed to Chemical Reactions Following Their Oxidation. Biochimica et Biophysica Acta-General Subjects, 157, 123-132. https://doi.org/10.1016/S0304-4165(02)00285-4

[40] Jovanovic, S.V., Steenken, S., Tosic, M., et al. (1994) Flavonoids as Antioxidants. Journal of the American Chemical Society, 116, 4846-4851.

https://doi.org/10.1021/ja00090a032

[41] Cuvelier, M.-E., Richard, H. and Berset, C. (2014) Comparison of the Antioxidative Activity of Some Acid-Phenols: Structure-Activity Relationship. Bioscience, Biotechnology, and Biochemistry, 56, 324-325. https://doi.org/10.1271/bbb.56.324

[42] Ivekovic, D., Milardovic, S., Roboz, M., et al. (2005) Evaluation of the Antioxidant Activity by Flow Injection Analysis Method with Electrochemically Generated ABTS Radical Cation. Analyst, 130, 708. https://doi.org/10.1039/b415939j

[43] Villaño, D., Fernández-Pachón, M.S., Troncoso, A.M., et al. (2005) Comparison of Antioxidant Activity of Wine Phenolic Compounds and Metabolites in Vitro. Analytica Chimica Acta, 538, 391-398. https://doi.org/10.1016/j.aca.2005.02.016

[44] Arrieta-Baez, D., Dorantes-Álvarez, L., Martinez-Torres, R., et al. (2012) Effect of Thermal Sterilization on Ferulic, Coumaric and Cinnamic Acids: Dimerization and Antioxidant Activity. Journal of the Science of Food and Agriculture, 92, 2715-2720. https://doi.org/10.1002/jsfa.5695

[45] Dykhuizen, R.S., Frazer, R., Duncan, C., et al. (1996) Antimicrobial Effect of Acidified Nitrite on Gut Pathogens: Importance of Dietary Nitrate in Host Defense. Antimicrobial Agents and Chemotherapy, 40, 1422-1425. https://doi.org/10.1128/AAC.40.6.1422

[46] Ward, G., Hadar, Y., Bilkis, I., et al. (2001) Initial Steps of Ferulic Acid Polymeriza- 
tion by Lignin Peroxidase. Journal of Biological Chemistry, 276, 18734-18741.

https://doi.org/10.1074/jbc.M009785200

[47] Niwa, T., Doi, U., Kato, Y., et al. (1999) Inhibitory Mechanism of Sinapinic Acid against Peroxynitrite-Mediated Tyrosine Nitration of Protein in Vitro. FEBS Letters, 459, 43-46. https://doi.org/10.1016/S0014-5793(99)01216-8 